\title{
CRIANÇAS E ADOLESCENTES: DOS DIREITOS FORMALMENTE RECONHECIDOS À INSUFICIÊNCIA DE SUA CONCRETIZAÇÃO E O CRESCENTE PROCESSO DE JUDICIALIZAÇÃO
}

CHILDREN AND ADOLESCENTS: OF THE RIGHTS FORMALLY RECOGNIZED TO THE INSUFFICIENCY OF HIS REALIZATION AND THE GROWING PROCESS OF JUDICIALIZAÇÃO

\section{Carla Rosane Bressan', Antonia Demetrioº}

RECEBIDO EM: 30/03/2020 | ACEITO EM: 01/04/2020

DOI: $10.5902 / 2317175843218$

\section{RESUMO}

O presente artigo busca refletir sobre o contexto contraditório de "direitos formalmente reconhecidos" e a insuficiência ou ausência de sua concretização via política pública. É nesse embate que tem crescido a busca de acesso aos direitos pela via da Justiça. Nesse ano de 2020, em que o Estatuto da Criança e Adolescente (ECA) completa 30 de promulgação, é fundamental pautar a presente discussão, uma vez que tem ocorrido o aumento dos processos de judicialização envolvendo as políticas sociais básicas, de modo especial no campo da criança e adolescente. Dessa forma, procura-se caracterizar a atenção à Educação Básica e à Saúde no âmbito das referidas políticas no Estado de Santa Catarina, levantando as principais faltas e/ou omissões da intervenção pública; e, como consequência, sinalizar o aumento de demandas que têm chegado ao Ministério Público Estadual (MP/SC) envolvendo essa área. Como resultado do estudo, verificou-se que entre 2014 e 2018 houve um aumento significativo no número de processos em tramitação no MP/SC envolvendo a atenção a crianças e adolescentes, sinalizando a ausência do Estado na oferta de políticas públicas universalizantes. Conclui-se ainda que, apesar de transcorridos trinta anos da promulgação do Estatuto, infelizmente crianças e adolescentes ainda continuam tendo seus direitos básicos violados.

Palavras-chave: Criança e Adolescente; Judicialização; Política Pública; Saúde; Educação.

\footnotetext{
1 Doutora em Sciences Économiques - Université Pierre Mendès France de Grenoble (2006).Atualmente professora do Departamento de Serviço Social nos Cursos de Graduação e Pós-Graduação em Serviço Social da Universidade Federal de Santa Catarina (UFSC).

2 Possui graduação em Serviço Social pela Universidade Federal de Santa Catarina (UFSC). Mestranda do Programa de Pós-graduação e Serviço Social -PPGSS/UFSC. Membro integrante do NECAD. Tem experiência na área do Serviço Social com ênfase na temática referente aos direitos da Criança e do Adolescente com experiência na elaboração e desenvolvimento de projetos.
} 


\section{ABSTRACT}

The present article looks to think about the contradictory context of formally recognized "rights" and the insufficiency or absence of his realization he was seeing public politics. It is in this crash that the access search has been growing to the rights for the road of the Justice. In this year of 2020, in which the Statute of the Child and Adolescent (ECA) 30 of promulgation complete, it is basic to rule the present discussion, as soon as there has been taking place the increase of the processes of judicialização wrapping the basic social policies, in special way in the field of the child and adolescent. In this form, it tries to characterize the attention to the Basic Education and to the Health in the context of the above-mentioned policies in the State of Saint Catherine, lifting the main lacks and / or omissions of the public intervention; and, like consequence, to signal the increase of demands that have been reaching the State Public Ministry (MPISC), involving this area. As result of the study, happened what between 2014 and 2018 there was a significant increase in the number of processes in tramitação in the MPISC wrapping the attention to children and adolescent, signaling the absence of the State in the provision of universal public policies. One concludes despite, although transcorridos thirty years of the promulgation of the Statute, unfortunately children and adolescent still continue having its violated basic rights.

Keyword: Children and adolescent; Judicialization; Public policy: Cheers; Education.

\section{Introdução}

As lutas da sociedade civil brasileira ganharam maior força com o processo de redemocratização do país, o qual trouxe maior visibilidade para as grandes demandas sociais, transformando-as em políticas públicas. As pautas de reivindicações construídas pelos movimentos sociais, associações e entidades de classe incluíram direitos civis, políticos e sociais como medidas que possibilitaram melhorias nas condições de vida da população, especialmente por meio de meIhorias nos direitos relativos a salários, à educação, à saúde e à assistência. Essas mudanças construídas pelos atores sociais, em grande parte, foram incorporadas na elaboração da Constituição Federativa do Brasil, promulgada em 1988.

Esse processo desencadeou significativas conquistas para área social, incluindo a promulgação de importantes leis. A primeira metade dos anos 1990 foi marcada com a aprovação da Lei Orgânica de Saúde (Lei n. 8.080/1990), Estatuto da Criança e do Adolescente (Lei n. 8.069/1990), Lei Orgânica de Assistência Social (Lei n. 8.742/1993). Essas conquistas possibilitaram criar um aparato legal que impulsionasse o desenvolvimento social pautado na inclusão, na perspectiva de romper com heranças clientelistas e assistencialistas adotadas historicamente pelo Estado brasileiro, objetivando construir um novo perfil de Estado. Este, segundo Couto (2010), como "provedor e garantidor" de políticas de proteção social. O Estado poderia ser um agente ativo do desenvolvimento social, como uma instância promotora de políticas públicas de abrangência universal numa perspectiva humanista de responder aos direitos sociais. A partir dos princípios e definições da Constituição Federal Brasileira (1988), foi dado início à elaboração de um sistema de proteção social numa lógica de universalidade em áreas significativas, a exemplo da área da criança e do adolescente. 
O marco legal que tem maior centralidade na proteção de crianças e adolescentes brasileiros foi aprovado mais especificamente há 30 anos e é amplamente conhecido como Estatuto da Criança e do Adolescente (ECA), promulgado em 13/06/1990. Ele consiste em uma lei infraconstitucional, que reconhece os direitos humanos voltados à criança e ao adolescente, representando significativo avanço, especialmente por introduzir a perspectiva da "proteção integral"," contrapondo-se à doutrina da "situação irregular" até então vigente.

Tendo em vista a necessidade de implementar a concretização dos pressupostos constantes no Estatuto, em 1992 iniciou-se no Brasil o debate acerca da estruturação de um sistema específico que efetivasse a política de garantia de direitos da criança e do adolescente como caminho para a proteção integral. Esse sistema deveria ser estruturado e articulado em rede, integrando as instâncias públicas governamentais e da sociedade civil, pois, segundo Baptista (2012), “essa estruturação não contemplaria uma política setorial apartada, mas iria ressaltar a perspectiva de integralidade da ação, que deveria cortar transversal e intersetorialmente todas as políticas públicas, incluindo neste sistema o campo da administração da justiça, ao lado do campo das políticas de atendimento" (p.190).

Esse debate se desenvolveu ao longo de uma década, todavia, somente em abril de 2006, a Secretaria Especial de Direitos Humanos e o Conselho Nacional dos Direitos da Criança e do Adolescente (CONANDA) aprovaram conjuntamente a Resolução $n^{\circ} 113$, que dispõe sobre os parâmetros para a institucionalização e o fortalecimento do Sistema de Garantia de Direitos ${ }^{5}$ (SGD) para Crianças e do Adolescentes. Com o reconhecimento do SGD ${ }^{6}$, novos desafios passaram a se apresentar, dentre eles, por exemplo, no campo da "promoção", a ação articulada entre diferentes políticas, o atendimento às necessidades previstas para essa faixa etária, o cumprimento das responsabilidades nas diferentes esferas de governo, dentre outras. Como também, no campo da "defesa", novos atores sociais, tais como o Ministério Público, passam a integrar o SGD da criança e do adolescente, sendo desafiados a atuar de forma vigilante na responsabilização.

É no espectro desse debate que se inscreve a presente reflexão, pois se vincula a um projeto de pesquisa em curso que aborda o aumento dos processos de judicialização (Ministério Público e Tribunal de Justiça de Santa Catarina) como meio encontrado pela população para a efetivação dos Direitos Socais Básicos (educação, saúde e assistência social) no âmbito da Família e da Infância?. Decorrente do referido projeto de pesquisa, inscreve-se o subprojeto de pesquisa que tem como objeto de estudo "As representações enviadas ao Ministério Público de Santa Catarina, no campo da efetivação dos direitos sociais das áreas

7 Projeto de pesquisa intitulado: "As Representações ao Sistema de Justiça Catarinense, a partir do Ministério Público e de seu Prosseguimento no Tribunal de Justiça de Santa Catarina, no que se refere à Efetivação dos Direitos Sociais Básicos no Âmbito da Família e Infância". Trata-se de projeto desenvolvido entre os núcleos de Estudos da Criança, Adolescente e Família (NECAD) e Núcleo de Pesquisa Interdisciplinar Sociedade, Família e Política Social (NISFAPS), vinculados ao Departamento de Serviço Social da Universidade Federal de Santa Catarina (UFSC), com apoio e financiamento do MCT. 
da educação e da saúde, atinentes à criança e ao adolescente" ${ }^{\prime \prime}$. Dessa forma, para o presente texto, foi selecionado um conjunto de dados e informações (coletados no âmbito do referido subprojeto) e que tem como finalidade registrar: que tipo de atenção tem sido desenvolvida pela Política Pública de Educação nos últimos cinco anos (entre os anos 2014 e 2018), tendo em vista o cumprimento do "direito à educação básica" emanado pelo ECA e LDB; e, no mesmo recorte temporal, a atenção desenvolvida pela Política Pública de Saúde, tendo em vista a garantia ao direito à atenção básica de saúde, conforme previsto no ECA, para crianças e adolescente do Estado de Santa Catarina; como, também, registrar que tipo de demandas (referentes às duas políticas públicas voltas a esse segmento) têm chegado ao Ministério Público Catarinense, entendendo essa ação como uma das alternativas que a população tem construído para fazer frente ao aprofundamento da ausência do Estado.

Registram-se, assim, como objetivos do presente artigo, caracterizar a atenção de educação e saúde no âmbito das referidas políticas estaduais, levantando as principais faltas e/ou omissões da intervenção estatal; assim como, também, identificar as demandas que têm chegado no Ministério Público Estadual, procurando dar visibilidade especificamente ao que se refere ao segmento da criança e do adolescente.

$\mathrm{O}$ artigo foi construído em duas partes. A primeira procura fazer a contextualização da temática, abordando rapidamente o reconhecimento dos direitos de crianças e adolescentes, e busca mais especificamente situar a dinâmica de organização das políticas públicas nas duas últimas décadas e a sua explícita subordinação à agenda econômica dos governantes. Na sequência, é abordado o crescente processo de judicialização das políticas socais básicas, priorizando o direito social à Educação Básica e à Saúde no contexto catarinense. Neste item abordam-se também as demandas que têm chegado até o Ministério Público Estadual, nas questões tocantes a crianças e adolescentes. Esse movimento tem a finalidade de demonstrar o dilema vivido atualmente entre "direitos formalmente reconhecidos" e a ausência do poder público na sua concretização. Como alternativa para essa equação, uma das saídas construídas tem sido apresentar a demanda na via da Justiça.

\section{Reconhecimento de direitos sociais $X$ políticas públicas de atenção a crianças e adolescentes: contextualizando a temática}

Apesar dos reconhecimentos legalmente registrados na Constituição Federal de 1988 e das ações deles decorrentes, o Brasil continua sendo um país de elevado índice de desigualdade social, que pode ser confirmada por meio dos dados estatísticos de pesquisas e estudos divulgados pelo IBGE (2019) ${ }^{9}$, os quais

80 presente consiste no projeto de investigação qualificado para a obtenção do grau de Mestre em Serviço Social, que se encontra em fase de desenvolvimento pela mestranda autora deste artigo e coordenado para orientadora, também autora do presente artigo.

9 IBGE. Síntese de Indicadores Sociais. Agência IBGE Noticias, 2019. Disponível https://agenciadenoticias. 
CRIANÇAS E ADOLESCENTES: DOS DIREITOS FORMALMENTE RECONHECIDOS À INSUFICIÊNCIA DE SUA CONCRETIZAÇÃO E O CRESCENTE PROCESSO DE JUDICIALIZAÇÃO

informam que a extrema pobreza atinge 13,5 milhões de pessoas, chegando ao maior nível em sete anos. As sínteses dos indicadores sociais apontam que, em $2018,13,5$ milhões de brasileiros viviam com renda mensal per capita inferior a $\mathrm{R} \$ 145,00$ reais. Esses indicadores são feitos com base no critério de U\$S 1,9 por dia, adotado pelo Banco Mundial para identificar as condições de pobreza.

Este é um contexto intrinsecamente relacionado com o atual estágio do capitalismo, que tem suas bases na centralização e na acumulação, desenvolvendo um quadro de elevada desigualdade social, assim quem detém o capital é quem tem as melhores condições de moradia, acesso aos recursos de saúde, educação (LÊNIN, 2012). Por outro lado, na engrenagem deste sistema perverso estão os trabalhadores que detêm unicamente a sua força de trabalho a ser vendida, de maneira que não detêm nem a renda, nem o capital. Em um contexto de desigualdade social, produzida primordialmente pela diferenciação econômica, "é tributário desta lógica o caráter volátil do crescimento que redundará em maior concentração de renda e aumento da pobreza, gerando um verdadeiro 'apartheid social'" (IAMAMOTO 2015, p. 142). Para a referida autora, essa lógica vem produzindo em países como o Brasil proporções de um verdadeiro "desastre social", atingindo diretamente as condições de vida da população. E ainda

Somam-se a esse quadro o analfabetismo, a baixa escolaridade média da população, a precariedade da qualidade do ensino básico, as elevadas taxas de mortalidade infantil, mortalidade materna e a mortalidade por causas externas, especialmente a violência e as questões de segurança (homicídios, crime organizado, precariedade do sistema de segurança e justiça criminal, entre outras) (IAMAMOTO, 2015, p. 155)

O quadro de desigualdade produzido por este sistema não proporciona o acesso a políticas fundamentais como saúde, educação, profissionalização, prejudicando ou até mesmo impedindo o desenvolvimento físico, psíquico e social de significativa parcela de crianças e adolescentes filhos da classe operária.

Segundo Ferraz ${ }^{10}$ (2019), dados divulgados pelas Nações Unidas têm indicado que a pobreza e a desigualdade social influenciam nas condições de vida dos filhos de pais pobres, possibilitando poucas oportunidades de escolha e desenvolvimento na infância e na adolescência. As consequências decorrentes deste quadro originam mais vulnerabilidade aos riscos de se tornarem vítimas do trabalho em condições análogas às de "trabalho escravo". Segundo a Organização Internacional do Trabalho (OIT), as situações de pobreza aumentam sobremaneira as possibilidades do trabalho infantil, além expor a criança e o adolescente a diversos outras situações de risco e desproteção. Neste sentido, o referido autor destaca que o ciclo vicioso e correlacionado do trabalho infan-

ibge.gov.br/agencia-noticias/2012-agencia-de-noticias/noticias/25882-extrema-pobreza-atinge-13-5-milhoes-de-pessoas-e-chega-ao-maior-nivel-em-7-anos. Acesso em 25 de mar. 2020.

10 Erik Ferraz - Oficial de projetos OIT - Organização Internacional do Trabalho, publicações site das Nações Unidas. Publicações referente ao Encontro Estadual sobre as Relações entre o Trabalho Infantil e Escravo realizado pela Secretaria do Desenvolvimento Social (SEDES), em São Luís/MA, em junho de 2019. Disponível em https://nacoesunidas.org/encontro-discute-relacao-entre-trabalho-infantil-e-escravo-no-maranhao/. 
til e escravo faz com que, no seio familiar, essas violações sejam perpetuadas por gerações, retroalimentando um ciclo de vulnerabilidade e pobreza.

As questões aqui levantadas acerca das relações sociais estabelecidas, especialmente as que dizem respeito ao plano econômico, responsáveis pela desigualdade social que atinge a criança e o adolescente, são intrinsecamente relacionadas com a particularidade do desenvolvimento social brasileiro como determinante para a compreensão da má distribuição de renda e, também, ausência de um padrão de proteção social que beneficie de forma universal a população.

Já no caso específico da criança e do adolescente catarinenses, os resultados recentemente lançados no documento "Diagnóstico da Realidade Social da Criança e do Adolescente do Estado de Santa Catarina" (2018) apontam o Estado de Santa Catarina com um percentual de domicílios com rendimento per capita de até 1/4 de salário mínimo por associação ${ }^{11}$, com desigualdade de 12,512. Estes dados reiteram que a desigualdade social está diretamente associada com a relação de poder e interesse da agenda política, que opta por privilegiar as pautas dos grandes setores econômicos em detrimento da área social.

É importante evidenciar que as raízes sociais brasileiras oriundas da colonização e escravização colocaram o país num quadro social deplorável e autoritário, que impôs a marginalização e a exclusão da maior parcela dos brasileiros, os quais nunca foram respeitados nem reconhecidos como cidadãos (GORENDER, 2016). As forças engendradas nas relações sociais, econômicas e políticas definiram um Estado com caráter burocrático, autoritário e clientelista, dominado pelas práticas políticas das camadas dirigentes. Nesta mesma direção, os longos períodos sob regime ditatorial deram continuidade e aprofundamento a estas características, de tal maneira, que nem mesmo o processo democrático possibilitou a ruptura com estas heranças estruturais e culturais tão fortemente engendradas na sociedade brasileira. Uma breve ilustração disto são as reflexões de Werneck (1999), em 1985, quando da morte de Tancredo Neves (presidente eleito) assume seu vice, José Sarney, com total apoio dos militares. Estes, de certa forma, continuarão dando a direção ao país, ancorados em um forte aparato estatal e jurídico que legitima e retroalimenta a continuidade das raízes de dominação e exploração da população. Cenário da década de 80 que se repete com a recente eleição para a Presidência da República ocorrida em 2018, que elegeu o Capitão Reformado Jair Messias Bolsonaro, representante da extrema direita e defensor da ditadura militar, reatualizando visceralmente a perspectiva conservadora enraizada em nossa história. Este se elege com um projeto explícito de desmonte das instituições públicas e dos direitos socialmente conquistados ${ }^{13}$. Projeto de desmon-

11 O Estado de Santa Catarina possui 295 municípios que se organizaram desde meados da década de oitenta em associações de âmbito regional. Atualmente conta-se com 21 Associações de Municípios no Estado e que estão vinculadas Federação Catarinense de Municípios (FECAM). Dessa forma é possível se obter dados e informações de forma agregada por regiões (territórios regionais). O referido Diagnóstico, utilizou como referência essa divisão territorial (amplamente conhecida e referenciada) para compatibilizar os dados de pesquisa.

12 É a diferença entre o maior e o menor valor para este indicador entre as associações.

13 Atualmente, além do capitão reformado que ocupa o cargo da presidência do país, o Vice-Presidente General Hamilton Mourão (também pertencente ao exército), de forma que foram nomeadas cerca de cem 
te das instituições públicas que encontra amplo suporte na perspectiva liberal ascendente nas décadas de 80 e 90 nos diferentes países e ampliado na atual perspectiva "ultraliberal"14 assumida pela gestão Bolsonaro.

Behring e Boschetti (2011) salientam que os anos 1970 e 1980 foram marcados por forte crise econômica que serviu de base para o movimento de reatualização do liberalismo, que se aprofundou significativamente a partir dos anos 1990 em todo o mundo. Muito embora a década de 80 represente um divisor de águas na história brasileira, com importantes conquistas democráticas, especialmente para o campo social, a década subsequente avançou, segundo as referidas autoras, "dando novo fôlego às teses neoliberais, que atribuem a crise ao poder excessivo dos sindicatos, com sua pressão sobre os salários e os gastos sociais do Estado"(2011 p. 10). Decorrentes desse processo, desde então as políticas sociais têm sido constantemente submetidas a amplas reformas, mediante medidas e propostas que implicam na redução e perda de direitos já reconhecidos. Dessa forma, o processo de reestruturação produtiva implantado especialmente a partir dos anos 1990, caracterizado pelo ajuste liberal, em contextos como no caso brasileiro, implicou a desregulamentação dos direitos sociais, trabalhistas, corte de gastos no campo das políticas públicas, remetendo a satisfação de necessidades sociais à responsabilidade e ao mérito individual.

Conforme Couto (2010), as consequências da implantação do receituário liberal implicaram um desenho de políticas sociais com caráter emergencial, focalistas e assistencialistas, reatualizando o caráter meritocrático, da concessão e da dádiva, contrários às concepções de direito. Assim, de um lado, o quadro de reestruturação produtiva produziu uma série de desmontes das parcas conquistas sociais nas diferentes áreas sociais, tanto na área trabalhista, quanto das políticas sociais, influenciando significativamente nas condições concretas do cotidiano da classe trabalhadora. De outro, o aprofundamento da desigualdade e da pobreza vinculadas ao controle exercido pelas esferas dominantes não representa mero acidente, pelo contrário, cumpre funções bem específicas que atingem a organização coletiva, debilitando as possibilidades da crítica e do questionamento.

Segundo Werneck (1999), muito embora a luta pela afirmação e reconhecimento de direitos seja contínua na história da população brasileira, "homens e mulheres ficaram à mercê do favor pessoal, sujeitos a dependência patrimonial e às políticas de clientela" (p.150). Estes elementos enraizados na formação social brasileira foram decisivos no delineamento e formatação das políticas sociais que ainda hoje apresentam resquícios de clientelismo e assistencialismo, desvinculadas da concepção de direito, apesar de serem fruto de

pessoas com origem nas forças armadas para diferentes postos e ministérios. Desse total, 46 estão em posições estratégicas. Exemplo disso são as oito nomeações realizadas pelo presidente imediatamente após a posse para os cargos Ministro de Estado com procedência militar, repetindo a mesma situação já vivenciada pelo Brasil em outros momentos históricos.

14 Termo utilizado por Mészarós (2002) relativo à radicalidade com que os liberais do século XXI agem para obtenção da hegemonia. 
árduas conquistas das lutas da classe trabalhadora. Para o referido autor este fenômeno encontra explicações decorrentes das especificidades da formação cultural, econômica, política e social da sociedade brasileira.

\begin{abstract}
Na sociedade brasileira, um caso de capitalismo retardatário e de democracia política incipiente, a presença do direito e de suas instituições, mais do que indicativa de um ambiente social marcado pela desregulação e pela anomia, é a expressão do avanço da agenda igualitária em um contexto que, tradicionalmente, não conheceu as instituições da liberdade. Neste sentido, o direito não é "substitutivo" da república, dos partidos e do associativismo - ele apenas ocupa um vazio, pondo-se no lugar deles, e não necessariamente como solução permanente. Décadas de autoritarismo desorganizaram a vida social, desestimularam a participação social, valorizando o individualismo selvagem, refratário a cidadania e a ideia de bem-comum. A intervenção normativa e a constituição de uma esfera pública vinculada direta ou indiretamente ao judiciário, como no caso das ações pública e dos Juizados Especiais, em vez de manterem os indivíduos à parte da república pode se constituir, dependendo dos operadores sociais, em uma pedagogia para o exercício das virtudes cívicas (p.150).
\end{abstract}

Pereira (2016) vai salientar que esta lógica capitalista calcada na austeridade social e na precarização dos salários e flexibilização das leis justifica as políticas neoliberais de proteção social, marcadas por políticas residuais e seletivas. Para a autora, embora as medidas de proteção social antecedam o capitalismo e tenham sido ampliadas nas últimas décadas, as desenvolvidas nesse modo de produção são permeadas pela regulação na lógica do controle, numa relação contraditória entre capital e trabalho, Estado e sociedade. Isto significa que a proteção social no capitalismo não está inteiramente comprometida com as necessidades sociais e, para além de permitir o acesso a bens e serviços, contribui estrategicamente para a manutenção e continuidade deste sistema, ofertando serviços de forma restrita, focando tão somente a manutenção da força produtiva. Segundo a referida autora, tal lógica permite políticas residuais num "padrão de proteção social mínimo, focalizado nos extremamente pobres, deslocada do status de direito e que se constrói e desenvolve em relutância por parte de governos, legisladores, gestores e executores dos países onde ela se processa"(p. 91). Assim, esses locus de "reprodução das ideologias burguesas acabam por destruir qualquer possibilidade de satisfação das necessidades humanas como questão de direito socialmente legitimado" (p. 91).

É esse movimento que pode ser observado no contexto brasileiro nas últimas décadas, em que os governos realizam diversas contrarreformas com o objetivo de cortar gastos sociais, utilizando os recursos prioritariamente em agendas que favorecem o grande capital. Em suma, o capital tem avançado sobre o fundo público e direcionado os recursos para o pagamento da dívida pública e financiado o grande capital. 
Essas questões atravessam tanto a formulação como a implantação das políticas públicas agravadas pelas crises econômicas que incidem diretamente sobre os recursos financeiros destinados a financiar políticas públicas, de forma que é possível evidenciar o descompasso entre direitos legalmente assegurados nas décadas de 80 e 90 e os limites encontrados no processo de concretização do direito.

O enxugamento dos recursos destinados para as políticas e serviços públicos colabora para a precarização e ineficiência destes, expandindo as condições para ações no campo da filantropia ou então para o clássico movimento de privatização das esferas estatais (nas mais diferentes áreas), avançando especialmente sobre os setores dos serviços e das políticas públicas, incluindo, sobretudo, as áreas da educação e da saúde.

A exemplo desse processo, de um lado temos crianças e adolescentes que, embora tenham seus direitos reconhecidos e reafirmados, atualmente continuam a ter seus direitos violados, constituindo o reflexo das expropriações, das assimetrias e das contradições das relações sociais e econômicas vigentes, comandadas pelas regras de acumulação, expressas na retração do orçamento destinado à área social. Perspectiva esta que desconsidera os preceitos da Proteção Integral, então previstos nas mais diferentes regulamentações vigentes, em que se reafirma que a criança e o adolescente constituem-se em "sujeitos de direitos" e são incapazes de se defender, especialmente por se encontrarem em fase peculiar de desenvolvimento, sendo então de absoluta responsabilidade do público adulto.

\section{Política de educação e saúde no Estado de Santa Catarina, o direito de crianças e adolescentes e o crescente processo de judicialização}

O atual contexto mundial de aprofundamento da perspectiva conservadora se apresenta com um projeto fortemente agressivo e destrutivo para o campo social, incidindo sobre as diversas políticas públicas, especialmente aquelas que representam importante oportunidade lucrativa para o capital. Neste cenário, as políticas de educação e saúde se tornaram campos de crescentes investidas de cortes de recursos, voltados principalmente à redução da atenção em nome da "contenção dos gastos públicos", isso justamente na contramão do que a necessidade impõe, uma vez que se presencia um crescente empobrecimento populacional e, por conseguinte, um aumento de população demandante de atenção dos serviços públicos básicos. Neste contexto, inegavelmente crianças e adolescentes têm constantemente negado o direito à formação e ao seu bem-estar.

Com intuito de dar forma concreta ao que se indica anteriormente, vamos abordar de modo especial os dados gerais da Política de Educação e de Saúde no Estado de Santa Catarina. Tomaram-se como referência os dados 
que estão disponíveis nas fontes oficiais (respectivas Secretarias de Estado), trazendo um recorte a partir de indicadores mais gerais de cada política. Como, também, o documento publicado pelo Conselho Estadual de Direitos da Criança e do Adolescente (CEDCA), denominado "Diagnóstico da Realidade Social da Criança e do Adolescente do Estado de Santa Catarina"15", divulgado em 2019, em que contém inúmeras informações quanto à situação da infância e adolescência nos mais diferentes campos sociais. Para a Política de Educação, delimitaram-se os índices de acesso e infrequência escolar; e, na Política de Saúde, foram priorizados as internações e motivos das internações. Justifica-se o motivo desse recorte tendo em vista os limites do presente artigo, como também pelos quantitativos mais significativos evidenciados nas demandas identificadas posteriormente, quando da análise das demandas que chegam até ao Ministério Público Catarinense.

Segundo o referido diagnóstico (CEDCA, 2018), o Estado de Santa Catarina conta com uma população total de 6.248 .436 habitantes, dentre estes, a população na faixa etária de 0 a 17 anos é de 1.687.643, correspondendo a $27,0 \%$ da população geral. Este número, que chega a ser representativo no contingente populacional, corresponde de forma praticamente equivalente em sua distribuição por faixas etárias aos dados registrados pelos índices nacionais, conforme a tabela que se segue:

Tabela 01 - Crianças e Adolescentes no Estado de Santa Catarina

\begin{tabular}{llll}
\hline Faixa etária & $\begin{array}{l}\text { Total em Santa } \\
\text { Catarina }\end{array}$ & $\begin{array}{l}\text { Porcentagem Santa } \\
\text { Catarina }\end{array}$ & Porcentagem Brasil \\
\hline De $\mathbf{0}$ a $\mathbf{5}$ anos & 491.530 & $7,90 \%$ & $8,80 \%$ \\
\hline De $\mathbf{0 6}$ a $\mathbf{1 1}$ anos & 556.054 & $8,90 \%$ & $9,90 \%$ \\
\hline De $\mathbf{1 2}$ a $\mathbf{1 7}$ anos & 640.059 & $10,20 \%$ & $10,80 \%$ \\
\hline De 0 a 17 anos & 1.687 .643 & $27,0 \%$, & $29,50 \%$ \\
\hline
\end{tabular}

Tabela elaborada pela pesquisadora.

Fonte: Diagnóstico da Realidade Social da Criança e do Adolescente do Estado de Santa Catarina. (CEDCA, 2018).

Conforme o quadro apresentado, o percentual da população na faixa etária de 0 a 5 anos corresponde a 7,9\% no Estado de Santa Catarina. A população na faixa etária de 6 a 11 anos representa 8,9\% da população. Estes dois referenciais estão abaixo do quantitativo nacional. No que se refere à faixa etária de 12 a 17 anos, corresponde a 10,2\% da população catarinense, muito próximo ao índice nacional.

Os dados sugerem que o quantitativo de crianças e adolescentes no estado é representativo e distribuído proporcionalmente nas diferentes faixas etárias, o que significa dizer que há necessidade de fornecer políticas públicas que atendam às diferentes faixas etárias, ou seja, tanto para crianças quanto

15 O referido diagnóstico foi elaborado tomando como referência os dados brutos registrados no período entre 01/01/2016 e 31/12/2016, obtidos de toda a rede de atendimento à criança e ao adolescente do Estado de Santa Catarina e disponíveis nas diferentes Secretarias de Estado. Foram também utilizados dados do IBGE Censo demográfico 2010 (agregados e microdados). (CEDCA, 2018). 
para adolescentes ${ }^{16}$. E que estes precisam ter seus direitos sociais contemplados, principalmente $o$ acesso às diferentes políticas públicas que possibilitem o atendimento integral às necessidades da população na faixa etária de 0 a 17 anos.

No que se refere mais especificamente às duas políticas sociais aqui abordadas, denota-se, no caso da educação, a atenção na etapa da Educação Básica ${ }^{17}$ (conforme previsto pela LDB); e, no caso da saúde, às situações mais incidentes nessa faixa etária e que levam crianças e adolescentes a adentrarem ao sistema público de saúde no nível de alta complexidade ${ }^{18}$.

No que se refere ao campo educacional, os dados de atenção na educação básica, quando se trata de crianças e adolescentes matriculados na rede pública e privada de educação do Estado de Santa Catarina, segundo o documento "Indicadores Educacionais de Santa Catarina"19"(SED, 2018), apontam que em 2017 foram registradas $1.532 .825^{20}$ matrículas na educação básica, sendo distribuídas conforme a tabela que se segue:

Tabela 02 - Matrículas na Educação Básica em Santa Catarina

\begin{tabular}{ll}
\hline Etapa do Ensino & $\begin{array}{l}\text { Número de } \\
\text { Matrículas }\end{array}$ \\
\hline Educação Infantil & 350.848 \\
\hline Ensino Fundamental & 843.520 \\
\hline Ensino Médio & 221.744
\end{tabular}

Tabela elaborada pela pesquisadora

Fonte: Indicadores de Acesso à Educação Básica e Superior no Estado de Santa Catarina. (SED, 2018).

Se fizermos a comparação entre os números da população da faixa etária de 0 a 5 anos, de 6 a 11 anos e de 12 a 17 anos (indicados anteriormente na Tabela 01), correspondente à etapa da educação infantil, do ensino fundamental e médio, é possível verificar registrada uma diferença de cerca de

16 Segundo o Estatuto da Criança e do Adolescente (1990), em seu art. $2^{\circ}$, considera-se criança a pessoa até 12 anos de idade incompletos, e adolescente aquela entre 12 e 18 anos de idade.

17 Segundo a Lei Nacional de Diretrizes e Bases da Educação Nacional (Lei n.9.394/1996), em seu art. 22, a educação básica tem por finalidades desenvolver o educando, assegurar-lhe a formação comum indispensável para o exercício da cidadania e fornecer-lhe meios para progredir no trabalho e em estudos posteriores. Quanto à sua composição, segundo o art. 23, a educação básica poderá organizar-se em séries anuais, períodos semestrais, ciclos, alternância regular de períodos de estudos, grupos não seriados, com base na idade, na competência e em outros critérios, ou por forma diversa de organização, sempre que o interesse do processo de aprendizagem assim o recomendar.

180 sistema público de saúde está previsto pela Lei $n^{\circ}$ 8.080. Especialmente indicado no art. $4^{\circ}$, o conjunto de aç̃es e servicos de saúde prestados por órgãos e instituições públicas federais, estaduais e municipais, da Administração direta e indireta e das fundações mantidas pelo Poder Público constitui o Sistema Único de Saúde (SUS). A gestão da saúde pública do Brasil é fragmentada e organizada em três níveis: primário, secundário e terciário. O primário é considerado a porta de entrada do SUS, composto pelas Unidades Básicas de Saúde (UBS), onde são marcadas consultas, exames básicos, procedimentos simples e feita a articulação com a comunidade nas escolas, centros comunitários e visitas domiciliares. No nível secundário da gestão da saúde estão as Unidades de Pronto Atendimento (UPAs), compostas por hospitais e outras unidades de atendimento especializado, ou de média complexidade, incluindo as unidades de urgência e emergência. No nível terciário encontram-se os hospitais de grande porte que atendem a alta complexidade.

19 Documento organizado e divulgado pela Diretoria de Política e Planejamento Educacional em 2018. Documento disponível na página da SED http://www.sed.sc.gov.br/servicos/indicadores-educacionais/ 28427-indicadores-educacionais acesso em 28 de abril de 2019.

20 Inclui matrículas do ensino regular, especial e/ou educação de Jovens e Adultos (EJA). O total de matrículas na educação básica é formado pela contagem das seguintes etapas de ensino: educação infantil ensino fundamental, ensino médio propedêutico, educação profissional-escolarização integrada, educação profissional - concomitante/FIC. Educação Profissional - Subsequente, educação de jovens e adultos - Ȩnsino fundamental e Educação de Jovens e Adultos - Ensino Médio. 
271.531 crianças e adolescentes em idade escolar e que não possuem matrícula na rede oficial de ensino (aqui considerando a pública e a privada). Mesmo se considerarmos as 61.655 matrículas do EJA (SED, 2018), ainda assim, persiste uma diferença de 209.876 em relação ao número da população na faixa etária de 0 a 17 anos.

Já o referido diagnóstico (CEDCA, 2018) registra que 18.999 crianças e adolescentes de 6 a 14 anos não frequentam a escola. Estima, ainda, que a população entre 15 e 17 anos contabilize 64.782 adolescentes fora da escola, incorporando um total de 83.781 crianças e adolescentes em idade escolar não frequentando o Ensino Fundamental ou Ensino Médio.

Em que pesem as diferenças numéricas (muitas vezes decorrentes de procedimentos metodológicos de coleta), é importante evidenciar que os dados revelam um número significativo de crianças e adolescentes fora da escola, índices concentrados nas faixas etárias em que a oferta do sistema de ensino é "obrigatória", isto tanto para a oferta pelo poder público, como também a frequência escolar (no caso do Ensino Fundamental) para a criança e o adolescente, sendo compulsório para seus responsáveis seu envio à escola. Há que se considerar, ainda, que aqui estamos tomando como referência os dados de "acesso", ou seja, de obter uma matrícula no sistema de ensino regular. Em que pese a importância desse ato, aqui não estão sendo consideradas as condições de "permanência" na escola, que vão desde a infraestrutura escolar (oferta de espaço físico, materiais didáticos, merenda, etc.), às condições de trabalho dos profissionais, como também à qualidade do ensino ofertado, pois todos são fatores que compõem qualitativamente o fenômeno abordado. E que, muito provavelmente, estão vinculados também a outros indicadores, tais como os índices de "abandono"21" ou "infrequência escolar"22, em que, segundo CEDCA (2018), no que se refere ao Ensino Fundamental, 579 crianças foram notificadas como infrequentes na escola. E, no Ensino Médio, 15.500 adolescentes abandonaram os estudos ao longo do ano de 2018. É importante considerar que essas crianças e adolescentes, embora estivessem adentrado o sistema de ensino (por um certo período), já se encontravam fora da escola ou em processo de abandono (infrequentes notificados), somando-se ao contingente populacional fora da escola.

Esses índices nos remetem a questionamentos preliminares tais como: por que estão fora da escola? Seria por falta de vagas? Seria por dificuldade de acesso? Seria por falta de materiais? Seria por necessidade de trabalhar? Ou por não considerarem a escola importante? Ou o que a escola oferece não corresponde aos seus interesses? Fugindo aos julgamentos e culpabilizações, fica evidente a necessidade de exercer maior vigilância quanto à oferta do sistema

21 Segundo Auriglietti (2014) abandono escolar se refere a deixar de estudar por um tempo e depois retornar aos estudos.

22 Segundo Pierrini; Santos (2016) a infrequência escolar se refere a um déficit na frequência escolar durante o ano ferindo as diretrizes da Lei no 9.394/1996, Lei de Diretrizes e Bases da Educação Nacional (LDBEN), que exige a frequência mínima de setenta e cinco por cento do total de horas letivas necessárias para a aprovação. 
público de educação catarinense, uma vez que um número significativo de crianças e adolescentes em idade escolar permanece à margem do sistema de ensino. Demonstra, também, que a política educacional vigente nos últimos cinco anos não consegue garantir o direito fundamental de "educação" a toda a população em idade escolar, deixando desprotegida uma parcela significativa de crianças e adolescentes na faixa etária de 0 a 17 anos.

Cabe também reafirmar a importância de um direito arduamente conquistado ao longo da história brasileira, que foi de estender o direito à educação básica de forma universal e de qualidade a todos. A Constituição da República Federativa do Brasil (1988) dedica o Capítulo III à educação, sob o título: Da Educação, Da Cultura e Do Desporto, que compreende os artigos 205 ao 214, determinando que a educação é direito de todos e dever do Estado, o que vai ser amplamente reafirmado como direito fundamental no ECA(1990). Temos na Constituição Federal:

Art. 205 A educação, direito de todos e dever do Estado e da família, será promovida e incentivada com a colaboração da sociedade, visando ao pleno desenvolvimento da pessoa, seu preparo para o exercício da cidadania e sua qualificação para o trabalho (BRASIL, 1988).

Nesse sentido, a educação é pautada no propósito de contribuir para o desenvolvimento pessoal, preparo para cidadania e qualificação profissional. O usufruto da educação, ao materializar-se, deve contribuir para o direito à vida cidadã, orientada pelo princípio do direito à igualdade. Na contramão disso, evidencia-se uma política educacional que exprime medidas educacionais condicionadas pelo contexto histórico social vivido no país, como muito bem nos indica Saviani (1998), indicando que a política educacional exprime as formas com que o Estado delimita suas políticas sociais. Na sociedade capitalista, a forma econômica vigente é a da propriedade privada dos meios de produção e sua consequente apropriação privada dos bens coletivamente produzidos, em virtude disso, as políticas sociais ficam subordinadas aos interesses econômicos, "favorecendo os interesses privados sobre os interesses da coletividade" (SANIANI, 1998, p. 01), resultando em sérias consequências, especialmente para as políticas sociais básicas, como é o caso da educação e da saúde, aqui abordadas.

No que se refere à Política de Saúde voltada ao referido segmento, segundo o "Diagnóstico da Realidade Social da Criança e do Adolescente do Estado de Santa Catarina" (CEDCA, 2018), a taxa de natalidade de Santa Catarina é de 13,8 nascidos vivos a cada mil habitantes, com um total de 95.310 nascidos vivos no ano de 2016.

Tomando como referência os indicadores delimitados anteriormente ocorrência de doenças e internações - segundo o referido diagnóstico em 2016 ocorreram 69.077 internações da população na faixa etária de 0 a17 anos, distribuídas nas seguintes faixas etárias: 
Tabela 03 - Internação de Crianças e Adolescentes no Estado de Santa Catarina

\begin{tabular}{ll}
\hline Faixa Etária & Quantidade de internações \\
\hline De 0 a 5 anos & 35.738 \\
\hline De 6 a 11 anos & 13.042 \\
\hline De 12 a17 anos & 20.297 \\
\hline Total & 69.077
\end{tabular}

Tabela elaborada pela pesquisadora.

Fonte de dados: Diagnóstico da Realidade Social da Criança e do Adolescente do Estado de Santa Catarina. (CEDCA, 2018).

Na faixa etária de 0 a 5 anos de idade, o principal motivo de internação é por doenças do aparelho respiratório, correspondendo a 33\% dos casos ( 11.793 internações); em segundo lugar aparecem as afecções originadas no período perinatal; e em terceiro lugar seguem-se as doenças parasitárias e infecciosas.

Ainda sobre as principais motivações para internação na faixa etária de 6 a 11 anos de idade, o principal motivo das internações continua sendo por doenças do aparelho respiratório, correspondendo a 20,9\% dos casos $(2.720$ internações). Como segundo motivo das internações nesta faixa etária estão as lesões, envenenamento e outras causas externas, e em terceiro lugar aparecem as doenças do aparelho digestivo.

Já, na faixa etária de 12 a 17 anos, a principal causa de internação é a gravidez, parto e puerpério, com $31,6 \%$ dos casos (6.421 internações); a segunda causa de internação nessa faixa etária é por lesões, envenenamento e outras causas externas; e em terceiro lugar as doenças do aparelho digestivo.

Dessa forma, temos como principal motivo de internação, por faixa etária, conforme registrado na Tabela 04:

Tabela 04 - Principal Motivo das Internações de Crianças e Adolescentes

\begin{tabular}{lll}
\hline Faixa etária & Principal motivo da internação & Quantidade \\
\hline De $\mathbf{0}$ a 5 anos & Doenças do aparelho respiratório & 11.793 \\
\hline De 6 a 11 anos & Doenças do aparelho respiratório & 2.720 \\
\hline De 12 a 17 anos & Gravidez, parto e puerpério & 6.421 \\
\hline Tabela elaborada pela pesquisadora
\end{tabular}

Fonte de dados: Diagnóstico da Realidade Social da Criança e do Adolescente do Estado de Santa Catarina. (CEDCA, 2018).

Tomando como referência os indicadores do CEDCA (2018), pode-se observar que a população na faixa etária entre 0 a 5 anos apresenta 13 motivos diferentes para internação, totalizando 35.738 internações registradas em 2016. Destas, a principal causa da internação foi por doença do aparelho respiratório, com 11.793 casos, representando $33,0 \%$ das causas das internações. Já na faixa etária entre 6 e11 anos aparecem 16 motivos para as internações, totalizando 13.042 internações em 2016, sendo que a principal causa das internações continua sendo por doenças do aparelho respiratório, com 2.720 ocorrências, representando $20 \%$ das causas. Importante destacar que há uma 
CRIANÇAS E ADOLESCENTES: DOS DIREITOS FORMALMENTE RECONHECIDOS À INSUFICIÊNCIA DE SUA CONCRETIZAÇÃO E O CRESCENTE PROCESSO DE JUDICIALIZAÇÃO

queda nos casos de internação entre as faixas etárias de 0 a 5 anos para as faixas etárias de 6 a 12 anos.

Segundo CEDCA (2018), na faixa etária de 12 a 17 anos aparecem 17 motivos para internação, totalizando 20.297 internações registradas em 2016. Gravidez, parto e puerpério lideram com 11.793 ocorrências, representando 31,6\% das causas. Nessa faixa etária as internações causadas por doenças do aparelho respiratório caem para a quinta posição, com 1.642 casos de internação.

Muito embora existam diferentes causas envolvidas nas doenças respiratórias, não se pode negar a possibilidade de as causas estarem associadas a baixa imunidade por desnutrição, falta de acesso à alimentação equilibrada, moradia digna, vestimentas adequadas ao clima das diferentes estações do ano, saneamento básico, entre outras condições dignas de satisfação das necessidades sociais. Estas sendo providas pelas mais diferentes políticas sociais estruturantes da vida social.

Nesse sentido, o conceito de saúde é incorporado de maneira ampliada e toma uma dimensão preventiva, para além da ausência da doença, ou, como indica Arouca (1987:36)

Não é simplesmente não estar doente, é mais: é um bem-estar social, é o direito ao trabalho, a um salário digno; é o direito a ter água, á vestimenta à educação, e até, a informação de como se pode dominar este mundo e transformá-lo. É ter direito a um meio ambiente que não seja agressivo, mas, que, pelo contrário, permita a existência de uma vida digna e decente; a um sistema político que respeite a livre opinião, a livre possibilidade de organização, e autodeterminação de um povo. É não estar todo o tempo submetido ao medo da violência, tanto daquela violência resultante da miséria, que é o roubo, o ataque, como a violência de um governo contra o seu próprio povo, para que sejam mantidos interesses que não sejam os do povo. (AROUCA, 1987, p. 36).

Segundo a Organização Mundial da Saúde (OMS), a saúde é o estado mais completo de bem-estar físico, mental e social e não apenas ausência de enfermidades, expressando o direito a uma vida com plenitude, apartada de privações (SCLIAR, 2007). Essa perspectiva vai influenciar determinantemente as discussões do campo da saúde nas décadas de 80 e 90 . E o debate vai nortear a agenda da $8^{\text {a }}$ Conferência Nacional de Saúde, ocorrida em março de 1986, em que foram estabelecidas as diretrizes para a elaboração do Sistema Descentralizado e Único de Saúde (SUS), onde a Saúde é vista como dever do Estado e direito do cidadão.

Este novo conceito de saúde é introduzido também no sentido da prevenção da doença, que, além de proporcionar o bem-estar físico, mental e social, torna-se menos onerosa para os cofres públicos. As ações decorrentes desta perspectiva e orientadas pela Lei $n^{\circ} 8.080$ definiram políticas públicas de saúde voltadas para a promoção da saúde tanto no campo econômico, quanto 
no campo social, no sentido de diminuir o risco de agravos à saúde, por meio de ações de promoção de saúde, proteção e recuperação, integrando ações assistenciais e preventivas (SÍCOLI; NASCIMENTO, 2003).

O reconhecimento da saúde como direito dos cidadãos e dever do Estado foi possível somente após a Constituição de 1988, que inaugurou "um novo sistema de proteção social pautado na concepção de Seguridade Social, que universaliza os direitos sociais, concebendo a Saúde, a Assistência Social e Previdência como constituidoras da segurança social, de responsabilidade do Estado" (BRAVO, 2007, p. 88).

A partir dos dados aqui registrados quanto a questões que envolvem a situação da infância e da adolescência, de modo especial no contexto das Políticas de Educação e de Saúde, delineiam-se elementos centrais e importantes a serem analisados tomando como referência o atual cenário brasileiro, ou seja, de estarem submetidos à lógica controladora dos gastos públicos (conforme pontuado anteriormente), uma vez que o compromisso com a universalização da atenção e o provimento de uma atenção de qualidade não está sendo garantido nos moldes preconizados na legislação vigente.

E é exatamente pela necessidade de buscar a concretização desses direitos (dentre outros) que tem ocorrido nas últimas décadas um significativo aumento do fenômeno de judicialização, como meio encontrado pela população para acessar determinados bens e serviços. De acordo com Werneck (1999), existe uma crescente demanda para o setor judiciário de questões vinculadas à garantia de direitos tanto sociais como civis. Este fenômeno tem se destacado especialmente a partir da década de 90 , período que se consagrou com a afirmação/reconhecimento dos direitos sociais na Constituição Federal de 1988. Pela primeira vez a população brasileira conquistou direitos como saúde, assistência social, educação e proteção estabelecida à criança, ao adolescente, ao idoso e à pessoa com deficiência, assegurados legalmente. Contudo, muito embora esses direitos tenham sido conquistados legalmente, não encontraram as condições objetivas de concretização por meio de políticas públicas responsáveis por garanti-los de fato, deixando grande parte da população desassistida de direitos mínimos necessários à vida com dignidade.

Em razão deste contexto contraditório de "direitos legalmente afirmados/reconhecidos" e a insuficiência, ou ausência, do poder público para atender às demandas da população, é crescente o movimento de construção de outras alternativas na busca do acesso aos direitos formalmente constituídos, agora, por meio da Justiça.

3.1 - A busca do acesso aos direitos formalmente constituídos - a construção de uma alternativa via a Justiça

O poder constituinte confiou ao Judiciário a interpretação e o controle da constitucionalidade das leis. O reconhecimento legal dos direitos nas Cons- 
tituições Republicanas permitiu que se instaurassem os processos de judicialização (WENECK, 1999). Neste sentido, embora os direitos sociais da família e da infância tenham sido assegurados formalmente, não encontraram as condições objetivas de concretização por meio de políticas públicas.

Este contexto que afirma direitos legalmente reconhecidos na Constituição, frente à ausência de respostas efetivas do poder público no atendimento das demandas da população, originou os processos de reivindicação de tais direitos por meio da Justiça. Esse fenômeno tem sido reconhecido atualmente como processo de judicialização das políticas sociais.

Segundo Esteves (2006), o processo de judicialização é um recurso das minorias contra as maiorias parlamentares na luta pelo acesso a políticas econômicas e de justiça social, fenômeno este muito associado à formação do Estado brasileiro, em que a

Parcela da população que pode contar com alei é pequena, mesmo nos grandes centros. Do ponto de vista da garantia dos direitos civis, os cidadãos brasileiros podem ser divididos em classes. Há os de primeira classe, os privilegiados, os "doutores", que estão acima da lei, que sempre conseguem defender seus interesses pelo poder do dinheiro e do prestígio social. Os "doutores" são invariavelmente brancos, ricos, bem-vestidos, com formação universitária. São empresários, banqueiros, grandes proprietários rurais e urbanos, políticos, profissionais liberais, altos funcionários. Frequentemente mantêm vínculos importantes nos negócios, no governo, próprio judiciário. Esses vínculos permitem que a lei só funcione em seu benefício. Em um cálculo aproximado, poderiam ser considerados "doutores" os $8 \%$ das famílias que, segundo a Pesquisa Nacional por Amostra de Domicílios (Pnad) de1996, recebiam mais de 20 salários mínimos. Para eles, as leis ou não existem ou podem ser dobradas (CARVALHO, 2018, p. 217).

Nessa direção, Sierra (2011, p.257) problematiza afirmando que, nas últimas décadas, houve um "aumento desmesurado de ações judiciais movidas por cidadãos que cobram o direito a proteção social", o que pode ser entendido como um caminho possível ao acesso a bens e serviços de saúde, educação e assistência social no atual contexto de avanço da política neoliberal e desmantelamento das políticas públicas em benefício dos setores privados, que buscam alargar a fatia de lucros, avançando sobre os setores públicos potencialmente lucrativos.

Segundo Andrade (2006) o poder judiciário integra um sistema de justiça com vários tentáculos formais - legislador, Mistério Público, advocacia, polícia, entre outros -, e informais - escolas, família, mercado de trabalho, religião. Via de regra, os caminhos de entrada das demandas no sistema de justiça podem ser de três formas. A primeira pode ser com o ingresso direto da ação judicial pelo cidadão que busca efetivar algum direito por meio da intervenção de advogado particular. Outro caminho de acesso pode ser pela 
intervenção de advogados públicos, por meio da Defensoria Pública, entre outros órgãos que disponibilizam este serviço gratuitamente. Ou ainda a via de acesso pode ocorrer por intermédio do Ministério Público, que pode ser acionado pelo usuário diretamente ou pelos profissionais dos serviços públicos que prestam atendimento àquele usuário.

Quanto ao Ministério Público, que se constitui locus da presente pesquisa, de acordo com a Constituição da República vigente, é uma instituição autônoma, incumbida de defender a ordem jurídica, a democracia e os interesses sociais e individuais indispensáveis. A partir da missão que cabe ao Ministério Público, de promover a efetivação dos direitos da sociedade, visando fortalecer a democracia e o desenvolvimento sustentável, é que esta instituição se torna um importante ator integrante dos Sistemas de Garantias dos Direitos (SGDs) no caso da criança e do adolescente. Ou seja:

Integrando a sociedade civil, o Ministério Público nos limites de suas atribuições, deve participar efetivamente, do processo democrático, alinhando-se com os demais órgãos do movimento social comprometidos com a concretização dos direitos já previstos e a positivação de situações novas que permitam o resgate da cidadania para a maioria ainda excluída desse processo, numa prática transformadora orientada no sentido da construção da nova ordem, da nova hegemonia, do projeto democrático (GOULART, 1998, p. 96).

Segundo Goulart (2013) o novo perfil que a Constituição definiu para o (MP) é de agente da vontade política transformadora, atribuindo-lhe também a função de promover valores associados a democracia.

O Ministério Público é o guardião dos direitos da sociedade e atua nas causas de interesse coletivo. Defende o interesse público e os direitos individuais indisponíveis. É uma instituição independente, que não integra o Poder Judiciário nem os Poderes Executivo e Legislativo (MP/SC, 2017, p. 09).

Dessa forma, salienta-se que uma das possíveis portas de entrada dos processos de judicialização dos direitos sociais seja a instância do Ministério Público, como no caso da presente pesquisa, em que a primeira etapa da coleta de dados (socializada neste artigo) busca demonstrar o efetivo crescimento da demanda ao Ministério Público catarinense das questões envolvendo a área da infância e juventude. Isso tudo na tentativa de obter respostas frente a direitos sociais então reconhecidos, e não concretizados pelas políticas públicas vigentes.

Nesse sentido, tomou-se como base de pesquisa (dessa primeira etapa) os dados disponíveis publicamente em documentos oficiais, mais objetivamente nos "Relatórios de Atividades Institucionais" disponibilizados no seu site oficial $^{23}$. Em vista dos limites do presente artigo, apresenta-se aqui uma síntese 
CRIANÇAS E ADOLESCENTES: DOS DIREITOS FORMALMENTE RECONHECIDOS À INSUFICIÊNCIA DE SUA CONCRETIZAÇÃO E O CRESCENTE PROCESSO DE JUDICIALIZAÇÃO

dos dados das Promotorias e da Procuradoria ${ }^{24}$, com o objetivo de demonstrar o efetivo crescimento nessa área, no período de 2013 a 2018, chamando a atenção para as questões que envolvem a área da infância e juventude.

Assim, os dados de ajuizamentos das Promotorias na área da Infância e Juventude, no período de 2013 a 2018, encontram-se em um crescente, ocorrendo aumento significativo nos três últimos anos. Especialmente com ações voltadas à defesa dos direitos de criança e do adolescente, conforme o que se segue, onde se registra o Ajuizamento das Promotorias na área da Infância e Juventude:

\section{Procedimentos e processos das Promotorias de Justiça na Área da Infância e Juventude}

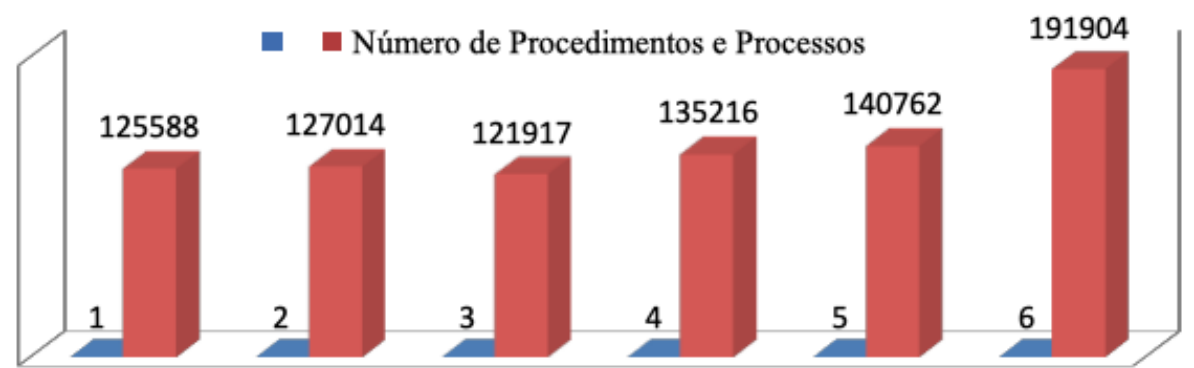

Gráfico elaborado pela pesquisadora a partir dos Relatórios de Atividades das Procuradorias e Promotorias de Justiça do Ministério Público do Estado de Santa Catarina.

Pode-se perceber que os ajuizamentos de questões no campo da defesa dos direitos da criança e do adolescente, no período de 2014 a 2016, se mantiveram quantitativamente em números bem próximos (nos diferentes anos), como também de forma bem semelhante aos ajuizamentos na área da defesa dos direitos individuais. Porém, identifica-se que, no ano de 2017, ocorreu um acréscimo significativo, em relação dos demais anos, como também em relação à área dos direitos individuais. Tal fato nos possibilita inferir que o campo da defesa dos Direitos de Crianças e Adolescentes tem sido motivador de maior intervenção das Promotorias Públicas, muito possivelmente fruto do seu envolvimento na discussão e vigilância frente ao que o ECA preconiza como necessidades/direitos para essa faixa etária.

O salto mais significativo ocorreu nos últimos três anos, conforme o Gráfico 02 , que se segue:

rio Público do Estado de Santa Catarina" organizados pela Corregedoria-Geral do Ministério Público de Santa Catarina, disponível https://www.mpsc.mp.br/corregedoria-geral-do-ministerio-publico/relatorios-anuais. 24 O Ministério Público Estadual organiza suas atividades em duas instâncias: de primeiro grau, que concentra as atividades das Promotorias, que estão divididas em diferentes áreas de atuação (civil, criminal, infância e juventude, direitos difusos e coletivos). E a instância de segundo grau, que se divide em justiça criminal e justiça cível. Esta última está dividida em diferentes áreas de atuação (direito administrativo, direito tributário ou fiscal, direito da infância e juventude, família e sucessổes, direitos difusos e recuperação judicial), contemplando ainda uma instância de ouvidoria institucional. 


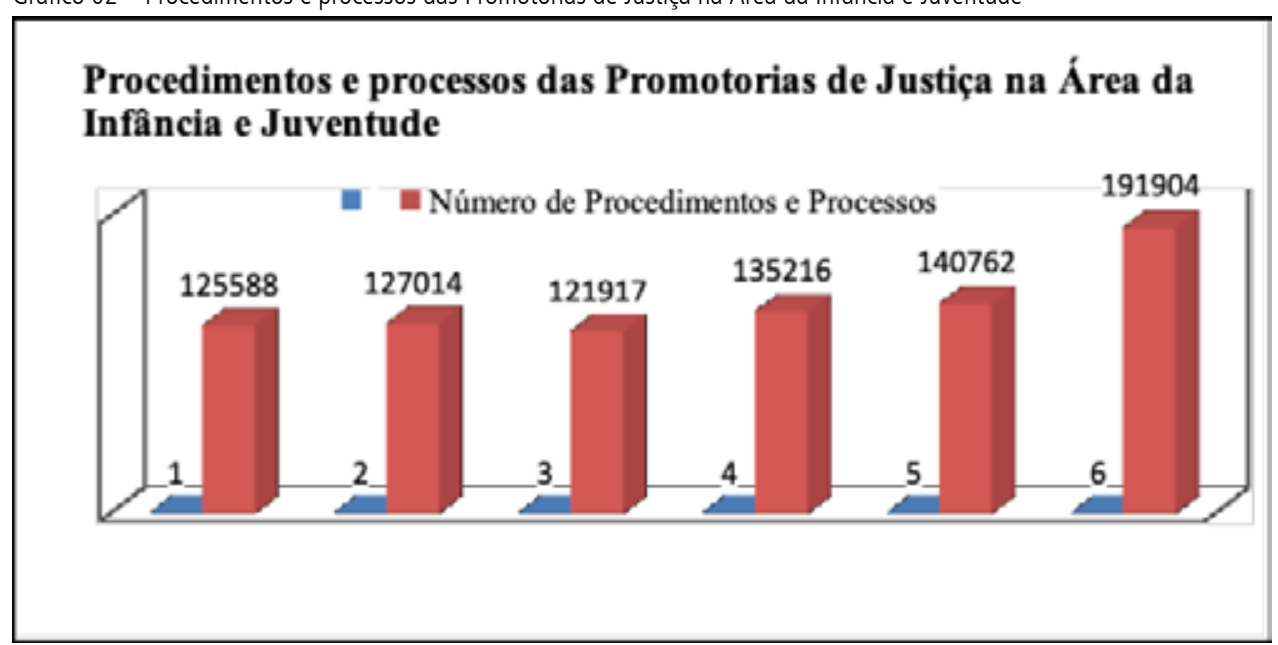

Gráfico elaborado pela pesquisadora a partir do Relatório de Atividades das Procuradorias e Promotorias de Justiça do Ministério Público do Estado de Santa Catarina.

Esse movimento de maior intervenção e/ou atuação das Promotorias Públicas (indicado anteriormente) demonstra o quanto o próprio Ministério Público tem assumido a questão como sendo um campo fundamental de cuidado e "Defesa" frente à violação de direitos reconhecidos. Reafirmamos aqui a importância desse envolvimento, uma vez que o Ministério Público - como integrante do SGD - assume um papel especial no atual momento da dinâmica social. Muito possivelmente fruto do seu envolvimento na discussão e vigilância frente ao que o ECA preconiza como necessidades/direitos para essa faixa etária. Ou ainda, como nas palavras de Silva (2005), a partir da Constituição da República Federativa do Brasil o "papel do Ministério Público, especialmente das Promotorias da Infância e Juventude ganhou impulso e autonomia" (p.44), principalmente em virtude do papel atribuído a esse órgão de fiscalização e aplicação de leis relativas à democracia. Neste sentido, a atuação do Ministério Público é bastante significativa para garantir a Proteção Integral de crianças e adolescentes, com "atuação presentificada na articulação, na promoção, na proteção" (p.44) dos Direitos Humanos de Crianças e Adolescente.

$\mathrm{Na}$ instância Procuradoria, o movimento que se apresenta reforça a premissa aqui indicada, de que a população tem buscado construir alternativas de busca da concretização de seus direitos. Identifica-se, por exemplo, que quando se trata da busca de canais de denúncias, estes têm sido considerados mais um espaço ao alcance do cidadão. Pode-se observar o crescimento significativo que vai ocorrer no recebimento de denúncias na ouvidoria do Ministério Público, conforme a tabela que se segue: 
CRIANÇAS E ADOLESCENTES: DOS DIREITOS FORMALMENTE RECONHECIDOS À INSUFICIÊNCIA DE SUA CONCRETIZAÇÃO E O CRESCENTE PROCESSO DE JUDICIALIZAÇÃO

Tabela 05 - Denúncias na Ouvidoria do Ministério Público de Santa Catarina

\begin{tabular}{cc}
\hline Ano & Denúncias na Ouvidoria (MP/SC) \\
\hline 2013 & 4.715 \\
\hline 2014 & 5.452 \\
\hline 2015 & 7.348 \\
\hline 2016 & 10.500 \\
\hline 2017 & 11.812 \\
\hline 2018 & 11.558
\end{tabular}

Tabela elaborada pela pesquisadora a partir do Relatório de Atividades das Procuradorias e Promotorias de Justiça do Ministério Público do Estado de Santa Catarina.

Esse crescimento reforça a perspectiva indicada pelos diferentes autores aqui referidos anteriormente, da crescente busca pela Justiça para obterem respostas que não têm sido ofertadas no cotidiano das relações institucionais. Muito embora, no atual estágio da pesquisa, os dados ainda não estejam desmembrados, podemos já fazer a "livre inferência" - a partir das informações que se conhece - de que um número significativo dessas denúncias está voltado à questão da não satisfação ou acesso a direitos sociais básicos, que deveriam estar sendo proporcionados pelas diferentes políticas públicas e que não têm ocorrido em sua efetividade.

Porém, esses dados são também no mínimo instigadores, pois, se observarmos os anos de 2016 a 2018, os números são significativos, e questionamos: o que é feito da denúncia? Que efetividade ela tem? O cidadão denunciante tem algum retorno? Se ela se refere à questão do campo da criança e do adolescente, como os diferentes atores do SGD são informados disso? Dentre muitas outras que esperamos poder responder com o avançar da pesquisa.

Dessa forma, diante da crescente ampliação desse fenômeno da judicialização da vida cotidiana, alguns pontos importantes merecem destaque. Primeiramente, segundo Werneck (1999), a invasão do direito em todas as relações sociais, até mesmo nas práticas sociais privadas, como o ambiente familiar, que sofre intervenção do Estado quando este, por exemplo, regula as formas de tratamento dos pais ou responsáveis para com os filhos. E o segundo está relacionado com o aspecto dialético do processo de judicialização, no qual as ações judiciais podem trazer o Poder Judiciário à cena para reivindicar o acesso a políticas públicas, contudo, simultaneamente, pode acionar a família para a responsabilização por seus membros, desconsiderando na maioria das vezes a sobrecarga sobre a família e as reais condições objetivas de que dispõe para assistir seus membros. Terceiro, os processos de judicialização podem, apesar de contraditoriamente, ser acionados tanto pela família, quanto pelos órgãos de proteção, incluindo as instâncias da criança e do adolescente, do idoso, da pessoa com deficiência, para reivindicar de qualquer lado o cumprimento das medidas de proteção e assistência, podendo, ao mesmo tempo, por um lado, operacionalizar as promessas cidadãs da Constituição de emancipação e, por outro lado, as promessas criminalizadoras da legislação penal. 
Segundo Andrade (2006, p. 2) o poder judiciário surge na Modernidade, portando um conjunto de promessas e funções de emancipação, na defesa de interesses e justiça, solução de conflitos, tendo como horizonte a luta pela efetividade dos direitos humanos e da cidadania. Contudo, diante das controvérsias e das diversas áreas de atuação, é necessário que a população exerça continuamente o papel de controle social na busca pela justiça social, especialmente para os grupos mais indefesos e vulneráveis, como é o caso da infância e adolescência.

\section{Considerações finais}

De modo geral, os dados apresentados e as problematizações tecidas nos remetem a Couto (2010), que afirma que o direito social é uma construção histórica. Contudo, apesar de a Constituição de 1988 representar um marco legal - como produto das lutas sociais, que conquistou a incorporação do atendimento das necessidades sociais, há que se reconhecer que, no contexto brasileiro, temos aspectos muito peculiares quanto à introdução dos direitos civis, políticos e sociais, que obedeceram a uma lógica inversa ao movimento ocorrido nos países europeus e norte-americanos. Nos países da América Latina, e no Brasil, especificamente, por mais que a classe operária tenha resistido, faltou uma "classe burguesa expressiva e uma classe operária ativa, com objetivos comuns e luta corporativa, o que permitiu a expansão de uma concepção vinculada ao favor, ao compadrio, que não encontrava eco na consolidação dos direitos" (COUTO, 2010, p. 184).

Infelizmente, essas concepções permanecem ainda hoje enraizadas na cultura brasileira, no que podemos observar, tendo como exemplo a área da criança e do adolescente, em que, mesmo após transcorridos trinta anos da promulgação do Estatuto da Criança e do Adolescente (ECA), ainda persistem sérios limites quanto à concretização dos pressupostos nele registrados.

Obviamente são inegáveis os avanços que se conquistou após a promulgação do Estatuto, especialmente relativos à mudança de perspectiva, introduzindo o princípio da Proteção Integral, que se opôs radicalmente à "doutrina da situação irregular" e às suas características anti-humanistas que feriam a dignidade da pessoa entre 0 e 18 anos, totalmente voltadas para o disciplinamento e dominação das crianças filhas da classe operária, então concebidas como ameaça social.

Conforme tangenciado anteriormente, uma nova estratégia construída pela população em busca do acesso aos direitos formalmente reconhecidos consiste no acionamento do Ministério Público para fazer frente à ausência do Estado. Ausência que se pauta principalmente na priorização da agenda político-econômica (que opta por privilegiar a agenda do grande capital) em detrimento das necessidades das áreas sociais. Esse movimento denuncia a ambiguidade entre direitos conquistados legalmente e a falta de políticas públicas universalmente abrangentes. 
CRIANÇAS E ADOLESCENTES: DOS DIREITOS FORMALMENTE RECONHECIDOS À INSUFICIÊNCIA DE SUA CONCRETIZAÇÃO E O CRESCENTE PROCESSO DE JUDICIALIZAÇÃO

Assim, se faz necessária uma atenta vigilância de Conselhos Municipais (CMDCAs), Estaduais (CEDCAs) e Conselho Nacional de Direitos da Criança e do Adolescente (CONANDA), com a sociedade civil organizada neles engajada, conjuntamente com demais movimentos sociais engajados nas lutas pela causa social (principalmente vinculados ao campo da criança e do adolescente), com intuito de constituir forças, fortalecendo as suas agendas, para que se tenha maior poder de barganha frente ao forte aparato das forças políticas que representam os interesses capitalistas.

Uma vez que, conforme preconizam a Constituição da República Federativa do Brasil (1988) e o Estatuto da Criança e do Adolescente (1990), a área da Criança e do Adolescente necessita de especial atenção, por se tratar de um público indefeso por si próprio e em fase peculiar de desenvolvimento, sendo de absoluta responsabilidade dos adultos, ou seja, são responsabilidade da família, do Estado e da sociedade em geral.

\section{Referências bibliográficas:}

ANDRADE, V. R. A colonização da justiça pela justiça penal: potencialidades e limites do Judiciário, na era da globalização neoliberal. Revista Katalysis, v. 9, n. 1, 2006, p.11-14.

AROUCA, Sergio. Saúde é Democracia. Anais $8^{a}$ Conferência Nacional de Saúde, 1986. Brasília: Centro de Documentação do Ministério da Saúde, 1987, p. 35-47.

AURIGLIETTI, Rosangela Cristina Rocha. Evasão e Abandono Escolar: Causas, conseqüências e alternativas - o combate à evasão escolar sob a perspectiva dos alunos. In: Os Desafios da Escola Pública Paranaense na Perspectivado Professor PDE. Paraná: 2014, v. 1, p. 1-21 Disponível em: http://www. diaadiaeducacao.pr.gov.br/portals/cadernospde/pdebusca/producoes_pde/2014/2014_ufpr_ped_artigo_ rosangela_cristina_rocha.pdf. Acesso em: 25 de mar. 2020.

BAPTISTA, Myrian Veras. Algumas reflexões sobre o sistema de garantia de direitos. Serviço Social e Sociedade. São Paulo: Cortez, n.109, jan/mar.2012.

BEHRING, Elaine Rossetti; BOSCHETTI, Ivanete. Política Social: fundamentos e história. São Paulo, Cortez, $9^{a}$ ed. 2011.

BRASIL. Constituição da República Federativa do Brasil. Brasília: Congresso. Senado. 1988. Disponível em: <http://www.planalto.gov.br/ccivil_03/constituicao/constituicao.htm>. Acesso em: 27 de junh. de 2019

BRASIL. Estatuto da Criança e do Adolescente. Lei n 8.069, de 13 de julho de 1990. Disponível em: <http:// www.planalto.gov.br/ccivil_03/LEIS/L8069.htm>. Acesso em: 27 de junho. de 2019.

BRASIL. Congresso. Senado Lei $\mathbf{n}^{\circ}$ 9.394, de 20 de dezembro de 1996. Estabelece As Diretrizes e Bases da Educação Nacional. Disponível em:<http://www4.planalto.gov.br/legislacao/legislacao-1/leis-ordinarias/ legislacao-1/leis-ordinarias/1996\#content>. Acesso em: 25 dez. 2019.

CARVALHO, José Murilo de. Cidadania No Brasil: o longo caminho. Civilização Brasileira 24a edição. Rio de Janeiro 2018.

CONSELHO ESTADUAL DA CRIANÇA E DO ADOLESCENTE. Diagnóstico da Realidade Social da Criança e do Adolescente do Estado de Santa Catarina. Florianópolis, 2018. SDS. Disponível em: http://www.sds. sc.gov.br/index.php/conselhos/cedca/diagnostico-da-realidade-social-da-crianca-e-do-adolescente-doestado-de-santa-catarina Acesso em 30 de julho de 2019.

COUTO, Berenice Rojas. O Direito Social e a Assistência Social na Sociedade Brasileira: uma equação possível? São Paulo Cortez, 2010. 
ESTEVES, D.C.R. Cidadania e judicialização dos conflitos sociais. Revista de Direito Público. V. 04. Nº2. Londrina: maio/ago, 2006, p. 41-54.

GORENDER, Jacob. O Escravismo Colonial. São Paulo: Expressão Popular, 2016.

IAMAMOTO, Marilda. Serviço Social em Tempos de Capital Fetiche. São Paulo, Cortez 2015.

LÊNIN, Vladimir Ilich. Imperialismo, Estágio Superior do Capitalismo. São Paulo, Editora Expressão Popular. 2012.

MÉSZARÓS, Istevan. Para Além do Capital: rumo a uma teoria da transição. São Paulo: Boitempo, 2002.

PEREIRA, Camila Potyara. Proteção social no Capitalismo: crítica a teorias e ideologias conflitantes. São Paulo, Cortez 2016.

PIERINI, Alechandre José; SANTOS, Sonia Maria Cardoso dos. O Combate à infrequência escolar de Crianças e Adolescentes: A participação da rede de proteção social no programa a Apoia. Revista Brasileira Multidisciplinar. São Paulo v. 19, n. 1, p. 92-107, jul. 2016. Disponível em: http://revistarebram.com/ index.php/revistauniara/article/view/369/330. Acesso em: 25 de mar. De 2020.

SECRETARIA DE ESTADO DE EDUCAÇÃO. Indicadores Educacionais de Santa Catarina. Diretoria de políticas e planejamento Educacional. Florianópolis, 2017. Disponível emhttp://www.sed.sc.gov.br/servicos/ indicadores-educacionais/28427-indicadores-educacionaisacesso em 29 de abr. de 2019

SíCOLI, Juliana Lordello; NASCIMENTO, Paulo Roberto do. Promoção de Saúde: concepções, princípios e operacionalização. In.: Rev. Interface - Comunicação, Saúde, Educação. v.7, n.12, 2003, p.91-112

SIERRA, V. M. A judicialização da política no Brasil e a atuação do assistente social na justiça. Revista Katalysis, v. 14 , n. 2, 2011, p.256-264.

SILVA, Maria Liduína de Oliveira e. O Estatuto da Criança e do Adolescente e o Código de Menores: descontinuidades e continuidades. In.: Revista Serviço Social e Sociedade. São Paulo Cortez, ano XXVI, n. 83 set. 2005. Pag. 30-48.

WERNECK VIANNA, Luiz. A judicialização da política no Brasil, In WERNECK VIANNA, Luiz et alii, A judicialização da política e das relações sociais no Brasil. Rio de Janeiro: Editora Revan, 1999, p. 47-70 